\title{
Trends in natural product research: PSE young scientists' meeting, Budapest 2019 biochemistry, molecular aspects and pharmacology of bioactive natural products
}

\author{
Judit Hohmann · Dezső Csupor
}

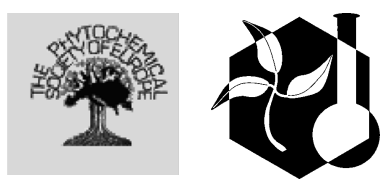

Published online: 5 November 2020

(C) Springer Nature B.V. 2020

This Special Issue of Phytochemistry Reviews is dedicated to the conference entitled "Trends in Natural Product Research: PSE Young Scientists' Meeting on Biochemistry, Molecular Aspects and Pharmacology of Bioactive Natural Products". The conference was held in Budapest in Hotel Benczúr on June 19-22, 2019, the organisers were Phytochemical Society of Europe, Institute of Pharmacognosy, Faculty of Pharmacy, University of Szeged, and Committee on Pharmaceutical Sciences, Hungarian Academy of Sciences.

The aim of the conference was to serve as a forum for discussions on trends, most current topics and latest results of natural product research, and bringing together senior scientists, young researchers, and $\mathrm{Ph} . \mathrm{D}$. students from all over the world. The scientific program included plenary lectures, short lectures and poster presentations. International reputable experts have delivered 15 plenary lectures and presented the state of the art and most significant scientific progresses in natural product science. Besides plenary lectures, 33 short lectures and 37 poster presentations focused on the following main scientific topics: plant biochemistry; molecular biology; natural products chemistry; metabolomics; phytochemical analysis;

J. Hohmann $(\bowtie) \cdot$ D. Csupor

Department of Pharmacognosy, University of Szeged,

Szeged, Hungary

e-mail: hohmann@pharm.u-szeged.hu bioactivity of natural products; pharmacology, and other related fields. Altogether 85 presentations were given at the meeting, and the edited book of abstracts was published (Hohmann et al. 2019). This international meeting brought together 102 attendees from 33 countries.

This Special Issue containing 10 reviews is drawn from some of the meetings featured lecture or any related field. The papers don't cover all relevant topics of the meeting but illustrate some of the ongoing research on natural products.

A very interesting review on the thia-Michael acceptor natural products offers an insight into the world of thiol-trapping natural products (Caprioglio et al. 2020). Li et al. (2020) summarized the progression and development of epigenetic manipulation in natural product research with the aim of engineering the secondary metabolites of fungi.

Four papers presented the results of systematic reviews of phytochemical and pharmacological data on certain taxa. The paper of Grauso et al. (2020) is an excellent overview of the literature data on stinging nettle, a popular medicinal and edible plant. The phytochemistry of oak polyphenols is summarized in a way that helps the reader to have a complex picture on this therapeutically important group of compounds (Söhretoglu and Renda 2020). ElNaker and her coauthors prepared the first overview on Arthrocnemum macrostachyum, a halophytic perennial shrub native to the Mediterranean basin (ElNaker et al. 2020). The 
genus Prangos, the members of which are widely used medicinal plants in Iran, is presented in a similar way by Mottaghipisheh et al. (2020).

The focus of two papers was the use of secondary metabolites in human therapy with new perspectives. The application of compounds with dual anti-inflammatory and antimicrobial effects may be promising in the treatment of infectious diseases (Sychrová et al. 2020), whereas Jivishov and Keusgen (2020) offers an overview on the anticancer activities of Allium species, including the metabolites responsible for these activities.

The paper of Rogowska and Szakiel (2020) is a comprehensive review of the role of sterols in plant defence reactions to environmental factors. Hellwig and Gasser (2020) summarizes the potential valorization methods of polyphenols from waste streams of marzipan production.

The Young Scientists' Meeting has obtained supports form several companies, such as Rowa Pharmaceuticals Ltd., Satco Ltd., Dr. Willmar Schwabe, PannonPharma, Phytolab, ABL\&E Group Laboratory Equipment and Thieme Medical Publishers. We would like to thank all our sponsors; without their help such an excellent congress would not be possible to organize. The great assistance of members of the scientific organizing committee (Randolph Arroo, Franz Bucar, Maria Jose U. Ferreira, Simon Gibbons, Efstathia Ioannou, Anna Kiss, Liselotte Krenn, Virginia Lanzotti, Francisco A. Macias, Satyajit Sarker, Veronique Seidel, Thomas J. Schmidt, Krystyna Skalicka Wozniak, Didem Söhretoglu, Miroslav Strnad, Rob Verpoorte) and local organizing committee (Szabolcs Béni, József Deli, Attila Hunyadi, Tivadar Kiss, Dóra Rédei, Andrea Vasas, Gábor Vasas) is highly appreciated.

During the meeting some bursaries and prizes were awarded. The prestigious Pierre Fabre-PSE Prize was delivered to Marc Diederich. This year PSE Travel Bursaries were given to Gokay Albayrak, Odeta Celaj, Afaf Al-Groshi, Shaymaa Al-Majmaie and Marie Pokorná. Young scientists, Johanna Gasser, Agata Rogowska, and Aimond Axelle were awarded with the Phytochemical Analysis/Wiley Prizes. Nóra Gampe received the Harborne Prize for her oral presentation, and OlchemIm Prize were given for the best poster presentations to Baloyi Itumeleng and Dóra Stefkó.
Thank you all authors of the present Special Issue for sharing their work and ideas about natural products, and contribute to the high standard of this volume. We also warmly acknowledge the work of the reviewers who have provided their valuable opinion. We would like to extend a very special thanks to Rob Verpoorte, the editor-in-chief of Phytochemistry Reviews, for giving us the opportunity to prepare this Special Issue.

\section{References}

Caprioglio D, Minassi A, Avonto C, Taglialatela-Scafati O, Appendino $G$ (2020) Thiol-trapping natural products under the lens of the cysteamine assay: friends, foes, or simply alternatively reversible ligands? Phytochem Rev. https:// doi.org/10.1007/s11101-020-09700-w

ElNaker NA, Yousef AF, Yousef LF (2020) A review of Arthrocnemum (Arthrocaulon) macrostachyum chemical content and bioactivity. Phytochem Rev. https://doi.org/10. 1007/s11101-020-09686-5

Grauso L, de Falco B, Lanzotti V, Motti R (2020) Stinging nettle, Urtica dioica L. Botanical, phytochemical and pharmacological overview. Phytochem Rev. https://doi. org/10.1007/s11101-020-09680-x

Hellwig V, Gasser J (2020) Polyphenols from waste streams of food industry - valorisation of blanch water from marzipan production. Phytochem Rev. https://doi.org/10.1007/ s11101-020-09663-y

Hohmann J, Kiss T, Csupor D (eds.) (2019) Trends in Natural Product Research-PSE Young Scientists' Meeting on Biochemistry, Molecular Aspects and Pharmacology of Bioactive Natural Products: Book of abstracts: Budapest, Hungary, June 19th-21st, 2019. Szeged, Hungary, Leicester, UK: Phytochemical Society of Europe, University of Szeged. 124 pp. https://doi.org/10.14232/tnpr.2019. af

Jivishov E, Keusgen M (2020) Can Allium chemical chest be a source of anticancer compounds? Phytochem Rev. https:// doi.org/10.5897/JMPR09.013

Li CY, Chung YM, Wu YC, Hunyadi A, Wang CCC, Chang FR (2020) Natural products development under epigenetic modulation in fungi. Phytochem Rev. https://doi.org/10. 1007/s11101-020-09684-7

Mottaghipisheh J, Kiss T, Tóth B, Csupor D (2020) The Prangos genus: a comprehensive review on traditional use, phytochemistry, and pharmacological activities. Phytochem Rev. https://doi.org/10.1007/s11101-020-09688-3

Rogowska A, Szakiel A (2020) The role of sterols in plant response to abiotic stress. Phytochem Rev. https://doi.org/ 10.1007/s11101-020-09708-2

Şöhretoğlu D, Renda G (2020) The polyphenolic profile of Oak (Quercus) species: a phytochemical and pharmacological overview. Phytochem Rev. https://doi.org/10.5897/ JMPR09.013 
Sychrová A, Koláriková I, Žemlička M, Šmejkal K (2020)

Natural compounds with dual antimicrobial and anti-inflammatory effects. Phytochem Rev. https://doi.org/10. 1007/s11101-020-09694-5
Publisher's Note Springer Nature remains neutral with regard to jurisdictional claims in published maps and institutional affiliations. 